\title{
Analysis of material recovery facilities for use in life-cycle assessment
}

Pressley, Phillip N.; Levis, James W.; Damgaard, Anders; Barlaz, Morton A.; DeCarolis, Joseph F.

Published in:

Waste Management

Link to article, DOI:

10.1016/j.wasman.2014.09.012

Publication date:

2015

Document Version

Peer reviewed version

Link back to DTU Orbit

Citation (APA):

Pressley, P. N., Levis, J. W., Damgaard, A., Barlaz, M. A., \& DeCarolis, J. F. (2015). Analysis of material recovery facilities for use in life-cycle assessment. Waste Management, 35, 307-317.

https://doi.org/10.1016/..wasman.2014.09.012

\section{General rights}

Copyright and moral rights for the publications made accessible in the public portal are retained by the authors and/or other copyright owners and it is a condition of accessing publications that users recognise and abide by the legal requirements associated with these rights.

- Users may download and print one copy of any publication from the public portal for the purpose of private study or research.

- You may not further distribute the material or use it for any profit-making activity or commercial gain

- You may freely distribute the URL identifying the publication in the public portal

If you believe that this document breaches copyright please contact us providing details, and we will remove access to the work immediately and investigate your claim. 
Accepted for publication in Waste Management

\section{Analysis of Material Recovery Facilities for Use in Life-Cycle Assessment}

Phillip N. Pressley, ${ }^{\mathrm{a},{ }^{*}}$, James W. Levis ${ }^{\mathrm{a}}$, Anders Damgaard ${ }^{\mathrm{b}}$, Morton A. Barlaz ${ }^{\mathrm{a}}$, Joseph F. DeCarolis ${ }^{\mathrm{a},{ }^{*}}$

${ }^{a}$ Department of Civil, Construction, and Environmental Engineering, NC State University, 2501 Stinson Drive, Raleigh, NC 27695, U.S.A

${ }^{\mathrm{b}}$ Department of Environmental Engineering, Technical University of Denmark, Bygningstorvet, Building 115, 2800 Kongens Lyngby, Denmark

* Corresponding author

Phone: +1 9195152331

Fax: +1 9195157908

E-mail: jdecarolis@ncsu.edu

"NOTE: this is the author's version of a work that was accepted for publication in Waste Management. Changes resulting from the publishing process, such as peer review, editing, corrections, structural formatting, and other quality control mechanisms may not be reflected in this document. Minor changes may have been made to this manuscript since it was accepted for publication. A definitive version is published in Waste Management, vol 35, pp 307-317, doi: 10.1016/j.wasman.2014.09.012" 


\title{
Analysis of Material Recovery Facilities for Use in Life-Cycle Assessment
}

\author{
Phillip N. Pressley ${ }^{\mathrm{a}, 1}$, James W. Levis ${ }^{\mathrm{a}}$, Anders Damgaard ${ }^{\mathrm{b}}$, Morton A. Barlaz ${ }^{\mathrm{a}}$, Joseph F. DeCarolis ${ }^{\mathrm{a}}$ \\ ${ }^{a}$ Department of Civil, Construction, and Environmental Engineering, NC State University, 2501 Stinson Drive, \\ Raleigh, NC 27695, U.S.A \\ ${ }^{\mathrm{b}}$ Department of Environmental Engineering, Technical University of Denmark, Miljøvej, 2800 Kongens Lyngby, \\ Denmark
}

\begin{abstract}
Insights derived from life-cycle assessment of solid waste management strategies depend critically on assumptions, data, and modeling at the unit process level. Based on new primary data, a process model was developed to estimate the cost and energy use associated with material recovery facilities (MRFs), which are responsible for sorting recyclables into saleable streams and as such represent a key piece of recycling infrastructure. The model includes four modules, each with a different process flow, for separation of single-stream, dual-stream, pre-sorted recyclables, and mixed-waste. Each MRF type has a distinct combination of equipment and default input waste composition. Model results for total amortized costs from each MRF type ranged from \$19.8 to \$24.9 per $\mathrm{Mg}$ (1 Mg = 1 metric ton) of waste input. Electricity use ranged from 4.7 to $7.8 \mathrm{kWh}$ per $\mathrm{Mg}$ of waste input. In a single-stream MRF, equipment required for glass separation consumes $28 \%$ of total facility electricity consumption, while all other pieces of material recovery equipment consume less than $10 \%$ of total electricity. The dual-stream and mixedwaste MRFs have similar electricity consumption to a single-stream MRF. Glass separation contributes a much larger fraction of electricity consumption in a pre-sorted MRF, due to lower overall facility electricity consumption. Parametric analysis revealed that reducing separation efficiency for each piece of equipment by $25 \%$ altered total facility electricity consumption by less than $4 \%$ in each case. When model results were compared with actual data for an existing single-stream MRF, the model estimated the facility's electricity consumption within $2 \%$. The results from this study can be integrated into LCAs of solid waste management with system boundaries that extend from the curb through final disposal.
\end{abstract}

Keywords: recycling; material recovery facility; life-cycle assessment; municipal solid waste

\footnotetext{
${ }^{1}$ Corresponding author. Tel.: +1 919515 2331; fax: +1 919515 7908. E-mail address: pnpressl@ncsu.edu (P. Pressley).
} 


\section{Introduction}

Life-cycle assessment (LCA) of solid waste management (SWM) alternatives requires a modeling framework that links detailed process-level operations within a broader system that can quantify impacts from waste generation through final disposal and resource recovery. The model described here has been used to develop material recovery facility (MRF) cost and energy consumption estimates for use in the Solid Waste Optimization Life-cycle Framework (SWOLF), which can be used to conduct LCA that optimizes the flow of different waste fractions within a prescribed system boundary across a set of userdefined time stages (Levis et al., 2013). However, the utility of such a framework depends critically on the quality and representativeness of process-level data used to characterize the unit processes within the system boundary. For complex unit processes such as landfills, anaerobic digesters, or MRFs, a single set of fixed industry-average data estimates cannot accurately predict the performance of individual facilities that include numerous design and operational choices and vary with waste composition. Improved estimates require unit process models that can relate different facility configurations and input waste compositions to changes in the resultant cost, energy consumption, and product flows, and such process models should be designed in a flexible manner to enable scenario exploration within a given LCA (Laurent et al., 2014). While existing inventory databases such as EcoInvent (2010) can provide aggregated inventory estimates for such processes, more representative assessments require specific knowledge of constituent sub-processes informed by state-of-the-art industry data.

The purpose of this paper is to present a detailed and novel process model that characterizes state-ofthe-art MRFs, which can be used for life-cycle modeling of SWM systems. MRFs are an integral part of the SWM system because they often determine the amount of collected recyclable material that can be recovered for recycling. Though their integration into the SWM system means that MRFs cannot be analyzed independently of the other SWM system components, detailed standalone MRF process models, like the one presented here, are essential to accurately model the life-cycle impacts of full SWM systems. Recyclable materials present in municipal solid waste (MSW) have increasingly gained the attention of SWM decision makers, as recycling of MSW can contribute to sustainability-related objectives including resource recovery, reduced energy consumption, and lower emissions. For example, the European waste framework directive created a 2020 recycling target of 50\% of MSW by mass for a number of fractions (EU, 2008). In the U.S., many states and cities have instituted landfill diversion goals. California and Florida have both set a 75\% diversion target for 2020 (California, 2012; FDEP 2010), while cities such as San Francisco, Oakland, and Seattle have set "zero waste” goals with the intent of eliminating landfill disposal (San Francisco Environment, 2013; Oakland, 2013; Seattle, 2013). In addition to increased waste 
diversion, the environmental benefits of recycling include the avoided use of virgin resources and energy savings (Merrild et al., 2012).

Only limited work has been done to systematically characterize MRF operations and the resulting emissions. Fitzgerald et al. (2012) quantified greenhouse gas emissions at 3 MRFs to compare the impact of dual versus single-stream facilities. However, the study did not consider system costs and it was not clear whether the purity of recovered materials was considered, as the presence of residual materials was higher than expected. Franchetti (2009) modeled MRF economics, but did not consider energy requirements or environmental emissions. Chester et al. (2008) examined the total system energy requirement and greenhouse gas emissions from implementing recycling strategies but did not model MRFs in detail. Themelis and Todd (2004) investigated recycling systems used in New York City, but did not quantify environmental impacts. With respect to MRF process models, Nishtala (1995) developed a model that quantified MRF costs and emissions, but it is now outdated because modern MRFs include several pieces of automated separation equipment that were not in use 20 years ago. Velis et al. (2013) used material flow analysis to analyze a solid recovered fuel process that is similar to the mixed-waste MRF modeled here. However, the input waste stream is bio-dried and shredded, so the results are not directly comparable. None of the aforementioned models allocate energy use and costs using a mass balance approach. The configuration and layout of MRF-related separation equipment depends critically on the input stream to the facility. MRFs can be designed to accept all recyclables in a single-stream, recyclables mixed with non-recyclables (mixed waste), recyclables separated into a fiber and non-fiber stream (dual stream), or pre-sorted recyclables. As a result, the waste stream type accepted by the MRF determines the required separation equipment, which in turn determines recovery efficiencies and energy requirements to run the equipment within the facility, which can then be used to build a MRF life-cycle inventory.

This study builds on previous work by developing a comprehensive, bottom-up model of MRFs that process (1) a single comingled recyclables stream, (2) mixed waste, (3) dual-stream and (4) pre-sorted recyclables. The resultant model is used to estimate MRF energy consumption and total cost. While the development of the MRF process model described here does not itself constitute an LCA, it is designed to be used within an LCA framework, and therefore needs to be informed by LCA considerations such as function, functional unit, system boundary, and allocation. Cost and energy are tracked both because environmental performance and cost are of interest to the recycling community, and they are required by SWOLF, which can use the total system-wide cost of SWM as an objective function or constraint. More broadly, we believe that LCA should include life-cycle costing if it is to be used to inform real world decisions that are largely driven by economics. This paper is organized as follows. Section 2 describes the modeling approach, including a discussion of the assumed system boundary and functional unit, and the 
data developed for this process model, which has been obtained largely through discussions with MRF operators and equipment vendors. Section 3 presents results from the different MRF types and draws insights from the analysis.

\section{Materials and Methods}

A spreadsheet-based LCA process model was developed to represent each of the four types of MRFs described above. Major inputs to the model include cost and energy consumption estimates for each piece of MRF equipment and the separation efficiencies for every modeled waste component associated with each piece of separation equipment, which are similar to the transfer coefficients used in Rotter et al. (2004) and Velis et al. (2010). MRF performance is directly related to the composition of the incoming waste stream, so a MRF process model should be capable of assessing performance associated with processing each waste component and accounting for changes to the incoming waste stream composition (e.g., waste with a higher ferrous fraction requires a larger magnet).

\subsection{System Boundaries and Functional Units}

The system boundary for each MRF process model begins at the tipping floor after waste is emptied from the collection vehicle. The boundary includes the production and combustion of all fuel used onsite, the production of all consumed electricity, and baling wire, which is a significant cost for MRFs (Combs, 2012). The system boundaries do not extend to the conversion of the recovered materials into new products or the offset from avoided virgin material production. The system boundaries are narrowly drawn around the MRFs to develop a detailed characterization of MRF life-cycle performance, which can be incorporated into solid waste LCAs with broader system boundaries (e.g., the entire solid waste system).

The function of all MRFs is to separate a waste stream into streams of saleable recyclables and a residual stream for final disposal that contains non-recyclable materials and non-recovered recyclables. The functional unit for each MRF type is $1 \mathrm{Mg}$ (1 Mg = 1 metric ton) of waste as-delivered to the MRF. Because the composition and number of streams delivered to each MRF type varies, the functional unit must be defined for each MRF type. Because the functional unit differs across MRF types, direct comparisons of energy consumption are not meaningful. The composition of waste arriving at each MRF type is shown in Table 1. The mixed-waste stream composition represents a complete residential waste stream. While the single-stream, dual-stream, and pre-sorted MRF compositions are identical, the number of streams delivered to each MRF type differs. Across these three MRF types, we assume that 
recycling program participation rates and source separation rates remain constant while only the number of waste streams changes. The assumed composition of the waste stream as-delivered to the MRF is based on the residential recycling composition of Seattle (Cascadia, 2011). The Seattle composition was selected because it includes glass recycling, unlike ODEQ (2011), and contaminants, unlike Beck (2005). The U.S. EPA Waste Characterization Report (2010), which reports a recyclable stream composition that includes all recovered materials, indicates that OCC (old corrugated containers) represents $40 \%$ of the recovered stream. Since most OCC is baled at commercial locations and is not mixed with the residential waste stream, this composition likely overestimates the significance of OCC at a MRF receiving residential recyclables. However, to capture the sensitivity of results to waste composition variation, the single-stream MRF model was run with the ODEQ (2011), Beck (2005), and U.S. EPA (2010) compositions to explore the sensitivity of the results to the inlet waste composition over a realistic range (Appendix A, Table A1). The resulting waste composition sensitivity analysis is discussed in Section 3.4. 
Table 1 Input Waste Composition for Each MRF Type

\begin{tabular}{|c|c|c|c|c|c|}
\hline \multicolumn{2}{|c|}{ Waste Fraction } & $\begin{array}{c}\text { Single- } \\
\text { Stream }^{\text {a }}\end{array}$ & $\begin{array}{c}\text { Dual- } \\
\text { Stream }^{\text {a }}\end{array}$ & $\begin{array}{c}\text { Pre- } \\
\text { Sorted }^{\mathrm{a}}\end{array}$ & $\begin{array}{l}\text { Mixed- } \\
\text { Waste }^{\mathrm{b}}\end{array}$ \\
\hline Organics & $\begin{array}{l}\text { Yard Trimmings, Leaves } \\
\text { Yard Trimmings, Grass } \\
\text { Yard Trimmings, Branches } \\
\text { Food Waste - Vegetable } \\
\text { Food Waste - Non-Vegetable } \\
\text { Wood } \\
\text { Textiles } \\
\text { Rubber/Leather }\end{array}$ & & $\begin{array}{l}0.0 \\
0.0 \\
0.0 \\
0.0 \\
0.0 \\
0.0 \\
0.9 \\
0.0\end{array}$ & & $\begin{array}{c}6.7 \\
5.0 \\
5.0 \\
13.8 \\
3.5 \\
5.0 \\
4.4 \\
0.5\end{array}$ \\
\hline Fiber & $\begin{array}{l}\text { Newsprint } \\
\text { Corr. Cardboard } \\
\text { Office Paper } \\
\text { Magazines } \\
\text { Third Class Mail } \\
\text { Mixed Paper } \\
\text { Non-Recyclable }\end{array}$ & & $\begin{array}{c}19.5 \\
17.8 \\
0.0 \\
0.6 \\
0.0 \\
29.7 \\
2.7\end{array}$ & & $\begin{array}{c}4.9 \\
14.5 \\
2.6 \\
0.8 \\
2.2 \\
0.0 \\
10.5\end{array}$ \\
\hline Plastic & $\begin{array}{l}\text { HDPE - Translucent Containers } \\
\text { HDPE - Pigmented Containers } \\
\text { PET - Containers } \\
\text { Film } \\
\text { Non-Recyclable }\end{array}$ & & $\begin{array}{l}1.1 \\
0.0 \\
2.1 \\
0.6 \\
2.1\end{array}$ & & $\begin{array}{l}0.4 \\
0.7 \\
1.3 \\
2.0 \\
5.6\end{array}$ \\
\hline Metals & $\begin{array}{l}\text { Ferrous Cans } \\
\text { Ferrous Metal - Other } \\
\text { Aluminum Cans } \\
\text { Aluminum - Foil } \\
\text { Aluminum - Other } \\
\text { Ferrous - Non-Recyclable } \\
\text { Aluminum - Non-Recyclable }\end{array}$ & & $\begin{array}{l}1.2 \\
0.4 \\
0.7 \\
0.2 \\
0.0 \\
0.4 \\
0.0\end{array}$ & & $\begin{array}{l}1.1 \\
0.2 \\
0.7 \\
0.2 \\
0.0 \\
0.0 \\
0.1\end{array}$ \\
\hline Glass & $\begin{array}{l}\text { Brown } \\
\text { Green } \\
\text { Clear } \\
\text { Non-Recyclable }\end{array}$ & & $\begin{array}{l}5.0 \\
7.1 \\
5.3 \\
0.3\end{array}$ & & $\begin{array}{l}2.7 \\
1.2 \\
0.8 \\
0.0\end{array}$ \\
\hline Miscellaneous & $\begin{array}{l}\text { Organic } \\
\text { Inorganic }\end{array}$ & & $\begin{array}{l}0.6 \\
1.5\end{array}$ & & $\begin{array}{l}0.0 \\
3.6\end{array}$ \\
\hline
\end{tabular}

${ }^{a}$ Single-stream, dual-stream, and pre-sorted waste compositions are based on Seattle's single-stream recyclable composition from Cascadia (2011).

${ }^{\mathrm{b}}$ Mixed-waste waste composition based on U.S. EPA (2012). 


\subsection{Process Descriptions}

Each MRF is designed to recover plastic film, OCC, other fiber such as newsprint, copy paper and third class mail, aluminum cans, ferrous cans, plastic film, HDPE (high-density polyethylene) and PET (polyethylene terephthalate) containers, and container glass. Because similar equipment often has multiple names, common U.S. industry-specific names are used throughout the description of the process flows and all equipment is described in Table 2. Because single-stream MRFs are common in the U.S., the single-stream process is described first, in detail. Discussion of how other MRF processes differ from the single-stream processes follows.

Table 2 MRF Terminology Descriptions

\begin{tabular}{ll}
\hline Process & \\
\hline 1-Way Baler & Compresses material (typically fiber) in one direction \\
2-Way Baler & Compresses material (typically containers) in two directions \\
Air Knife & Separates light materials from heavy materials via high pressure air \\
Drum Feeder & Opens bags and puts material on initial conveyor at a nearly constant rate \\
Eddy Current Separator & Uses magnetic fields to remove aluminum and other non-ferrous metals \\
Negative Sort & $\begin{array}{l}\text { Manually removes undesirable materials (contaminants); often used to } \\
\text { purify streams of recovered materials }\end{array}$ \\
Optical Sorter & $\begin{array}{l}\text { Identifies pre-determined material(s) using optical technology (e.g., } \\
\text { cameras, lasers, sensors) and removes the identified material from the } \\
\text { stream using bursts of compressed air }\end{array}$ \\
Laborers performing manual (positive or negative) sorts in a MRF \\
Pickers
\end{tabular}




\subsubsection{Single-Stream Process}

The single-stream process flow, presented in Figure 1, is designed to recover fiber, glass, metals, and plastic from a commingled recyclables stream. The equipment layout represents a general configuration based on a review and synthesis of visits to several single-stream MRFs currently in operation in the U.S. The collected recyclables are unloaded from arriving trucks on the tipping floor, where rolling stock (e.g., a front end loader) pushes material to a drum feeder. The drum feeder distributes material to the first belt conveyor at a constant rate, helping prevent the overload of downstream equipment. The first belt conveyor leads to a manual sort where large items and materials harmful to downstream equipment (e.g., wire) are removed for disposal. Additionally plastic film (i.e., plastic bags) is recovered with a vacuum and sent to the 2-way baler. All other materials continue to inclined Disc Screen 1 where OCC is recovered as it flows over the screen and is sent to the 1-way baler. The unders (i.e., material that goes through the screen) from Disc Screen 1 travel to inclined Disc Screen 2, where newsprint is separated from containers. The unders from Disc Screen 2, which are enriched in containers, fall on to a belt conveyor that leads to Disc Screen 3, which separates the remaining fiber from the container stream. Smaller sheets of fiber flow over Disc Screen 3, while containers and other materials fall through. The fiber streams separated by Disc Screens 2 and 3 proceed to a manual sort to remove contaminants before the streams are combined and sent to the 1-way baler. The composition of this fiber stream includes newsprint as well as all other fiber types accepted by the MRF. The unders from Disc Screen 3 proceed to a glass-breaker screen, where glass is broken into cullet, which falls through the screen with fines. The glass and fines go to an air knife that separates the fines and other light materials from the glass. The glass is sent to an optical sorter, where it is sorted by color. The colorseparated glass is then subjected to a manual sort, where ceramics and other contaminants are removed. 


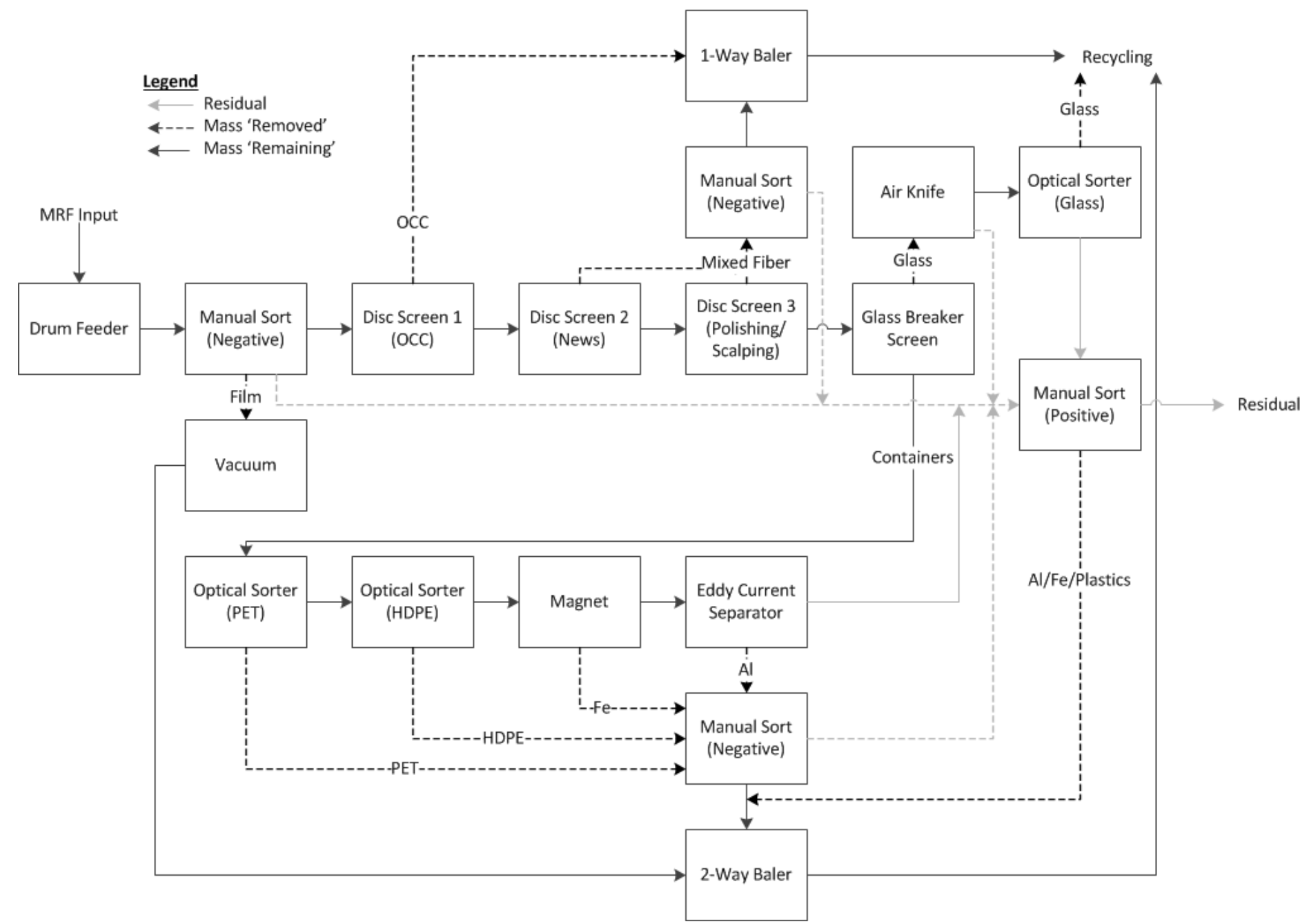

2 Figure 1 Single-stream MRF process flow. This equipment configuration is used to recover aluminum, ferrous, glass, HDPE containers, mixed 3 paper, OCC, PET containers, and plastic film from a commingled recyclable stream. All arrows represent belt conveyors except those ending at 4 'Recycling' and 'Residual'. 
The overs from the glass breaker screen are conveyed to an optical sorter that recovers PET. The 2 remaining stream is conveyed to a second optical sorter that removes all colors of HDPE. The remaining 3 stream proceeds to a magnet for ferrous recovery. The material remaining after the magnet proceeds to an 4 eddy current separator for aluminum recovery. The remaining residual stream goes to a manual sort, 5 where any recyclable materials missed by the separation equipment are recovered by pickers and sent to 6 the 2-way baler. All non-recovered material is transported offsite for final disposal.

7 The aluminum, ferrous, HDPE, and PET streams are separated and stored in cages prior to baling. 8 Each stream is inspected for contaminants prior to baling. Contaminants are combined into a residual 9 stream that is sent offsite for final disposal. Rolling stock is used throughout the facility to move 10 material. Individual pieces of rolling stock equipment are not modeled. Instead, all rolling stock fuel use 11 is modeled using a single coefficient in units of $\mathrm{L}$ fuel per incoming Mg. Equipment separation efficiencies are presented in Table 3. 
Table 3 Single-Stream MRF Separation Efficiencies (\%) ${ }^{\mathrm{a} b}$

\begin{tabular}{|c|c|c|c|c|c|c|c|c|c|c|}
\hline $\begin{array}{l}\text { Waste } \\
\text { Fraction }\end{array}$ & $\begin{array}{l}\text { Manual } \\
\text { Sort/ } \\
\text { Vacuum }\end{array}$ & $\begin{array}{l}\text { Disc } \\
\text { Screen } \\
1\end{array}$ & $\begin{array}{l}\text { Disc } \\
\text { Screen } \\
2\end{array}$ & $\begin{array}{l}\text { Disc } \\
\text { Screen } \\
3\end{array}$ & $\begin{array}{l}\text { Glass } \\
\text { Breaker } \\
\text { Screen }\end{array}$ & $\begin{array}{l}\text { Optical } \\
\text { Glass }\end{array}$ & $\begin{array}{l}\text { Optical } \\
\text { PET }\end{array}$ & $\begin{array}{l}\text { Optical } \\
\text { HDPE }\end{array}$ & Magnet & $\begin{array}{l}\text { Eddy } \\
\text { Current } \\
\text { Separator }\end{array}$ \\
\hline $\begin{array}{l}\text { OCC } \\
\text { Non-OCC }\end{array}$ & & 70 & 85 & 91 & & & & & & \\
\hline Fiber & & & 85 & 91 & & & & & & \\
\hline Plastic Film & 90 & & & & & & & & & \\
\hline HDPE & & & & & & & & 98 & & \\
\hline PET & & & & & & & 98 & & & \\
\hline $\mathrm{Fe}$ & & & & & & & & & 98 & \\
\hline $\mathrm{Al}$ & & & & & & & & & & 97 \\
\hline Glass & & & & & 97 & 98 & & & & \\
\hline
\end{tabular}

2

3 a Data represent the percentage of a material recovered by a given unit process. If manual separation is desired, the user can input separation 4 efficiencies into the appropriate manual sort option, and select manual separation instead of automated separation for the affected material. 5 However, glass may not be separated manually.

6 b Separation efficiency values were developed through expert judgment based on discussions with MRF operators and visual observation of MRF 7 equipment during operation. 


\subsubsection{Mixed-Waste Process}

The mixed-waste MRF process is identical to Figure 1 except a trommel screen is placed immediately after the drum feeder to remove organics and fines, as shown in Appendix A, Figure A1. Because the MSW stream contains more contaminants (i.e., non-recoverable materials such as food waste), equipment separation efficiencies are lower for mixed-waste MRFs than single-stream MRFs. Equipment separation efficiencies are presented in Appendix A, Table A2.

\subsubsection{Dual-Stream Process}

Dual-stream MRFs receive separate fiber and container streams from each collection vehicle. The dual-stream process flow is shown in Appendix A, Figure A2. The fiber stream in the dual-stream MRF is processed through the three disc screens as described for a single-stream MRF. However, the unders from disc screen 3 in the dual-stream MRF are collected as residual and transported offsite for disposal. Separation of the container stream begins with a drum feeder and is followed by a glass breaker screen, optical sorters, a magnet and an eddy current separator as in Figure 1. Because the two streams in the dual-stream MRF are treated separately, much of the equipment in a dual-stream MRF has a smaller throughput and capacity than a single-stream MRF for a stream with identical mass and composition. Equipment separation efficiencies are presented in Appendix A, Table A3.

\subsubsection{Pre-Sorted Process}

Pre-sorted MRFs accept source-separated streams of OCC, mixed paper, Al, Fe, HDPE, PET, and mixed glass. All streams except glass go to a manual sort to remove contaminants prior to baling, as presented in Appendix A, Figure A3. The glass stream is passed over a glass breaker screen to break bottles into cullet, which is then passed through an air knife for fines removal. The purified mixed glass stream continues to an optical sorter that separates glass by color. The glass then goes through a final manual sort to remove ceramics or any other contaminants harmful to downstream recycling. Equipment separation efficiencies are presented in Appendix A, Table A4.

\subsection{Recovered Material Specification and Separation Type}

The MRF process model has been developed to maximize flexibility. If a material is not recovered, the equipment used to separate it is omitted in the cost and emission calculations. For example, if aluminum is not recovered, the eddy current separator will be not be used. Additionally, users can override the default configuration for a given set of recovered materials to include or exclude any piece of modeled equipment. For example, a user could model a mixed-waste MRF without a trommel. 
To capture varying degrees of MRF automation within the spreadsheet model, each material can

2 be recovered manually via pickers or automatically via separation equipment. When a material is recovered manually, the corresponding separation equipment is replaced with a positive-sort picking station. For example, if OCC is recovered manually, Disc Screen 1, and the associated cost and electricity consumption, is replaced by a picking station where picker(s) recover cardboard. The only exception to this is glass, which is always separated using a glass breaker screen to minimize pickers' contact with sharp broken glass. Though the positive-sort picking station removes the same material(s) as the equipment it replaces, the corresponding input parameter values that describe the separation can be changed based on the presence of manual or mechanical separation. In this analysis, all material is recovered with automated equipment, but supplemented with negative manual sorts for stream purification.

\subsection{Mass Balance}

A mass balance is maintained throughout model calculations. The mass of each material fraction passing through each piece of equipment in each MRF type is tracked to estimate equipment throughputs (mass per hour), which determines equipment sizing. The separation efficiencies are organized in a matrix, like the one in Table 3. Data on separation efficiencies have not been published, so the values in Tables 3 and A3-A5 are based on expert judgment resulting from discussions with MRF operators and visual observation of MRF equipment during operation.

The mass of each waste fraction, $i$, removed by each piece of equipment, $j$, is calculated by multiplying the mass throughput $\left(m^{T P}\right)$ of $j$ by the separation efficiency of equipment $j$ for waste fraction $i$, as shown in Equation 1.

$m_{j, i}^{\text {removed }}=f_{j, i}^{\text {separation }} \cdot m_{j, i}^{T P}$

where:

$m_{j, i}^{\text {removed }}$

$f_{j, i}^{\text {separation }}$

$m_{j, i}^{T P}$ mass of waste fraction $i$ removed by equipment $j(\mathrm{Mg})$

separation efficiency of equipment $j$ for waste fraction $i$

incoming mass to equipment $j$ for waste fraction $i(\mathrm{Mg})$

When discussing mass throughput, we use units of mass $(\mathrm{Mg})$ and assume that the time associated with the mass flow is considered implicitly. Similarly, the mass of waste fraction $i$ remaining after equipment $j$ 
1 is calculated by subtracting the mass of waste fraction $i$ removed by equipment $j$ from the mass of waste

2 fraction $i$ input to equipment $j$, as shown in Equation 2:

$3 \quad m_{j, i}^{\text {remaining }}=m_{j, i}^{T P}-m_{j, i}^{\text {removed }}$

4

5

6

7

8

9

where:

$$
m_{j, i}^{\text {remaining }} \quad \text { mass of waste fraction } i \text { unaffected by equipment } j(\mathrm{Mg})
$$

The "mass removed" and "mass remaining" after equipment $j$ proceed to distinct downstream processes, as shown by the arrows leaving each box in Figure 1. The separation efficiency is based on the mass removed by equipment $j$.

\subsection{Diesel and Electricity Use}

Diesel and/or liquefied petroleum gas (LPG) are used by rolling stock and are input as L per incoming Mg. The diesel consumption values used in this analysis were derived from survey results in Combs (2012). Electricity consumption is calculated from the mass flow to each piece of equipment, $j$, and the electricity demand for equipment $j$ per unit mass of material processed. Designed maximum equipment throughput and motor data were first used to calculate electricity use per Mg throughput. To calculate the electricity use per $\mathrm{Mg}$ for equipment $j$, the motor size was multiplied by the fraction of motor capacity utilized and divided by the product of the maximum mass throughput and the fraction of equipment capacity utilized, which accounts for equipment processing less than maximum throughput, as shown in Equation 3. The fraction of motor capacity utilized accounts for motors operating at approximately $50 \%$ of their rated capacity when a piece of equipment is operating at maximum mass throughput, based on discussions with equipment manufacturers.

$E_{j}=\left(e_{j}^{\text {MaxMotor }} \cdot f_{j}^{M C}\right) /\left(m_{j}^{M T P} \cdot f_{j}^{M T P}\right)$

where:

$E_{j}$

$e_{j}^{\text {MaxMotor }}$

$f_{j}^{M C}$

$m_{j}^{M T P}$ electricity requirement of equipment $j$ (kWh per Mg)

motor size of equipment $j$

fraction of motor capacity utilized

maximum throughput mass of equipment $j(\mathrm{Mg})$ 
The MRF model assumes a linear relationship between the throughput of equipment $j$ and its electricity or fuel use and cost. For example, an eddy current separator processing two Mg of aluminum per hour would use twice the electricity and have double the cost of an eddy current separator processing one Mg of aluminum/hour. This assumption removes the need for specification of maximum facility throughput a priori. Therefore, the total resource use is automatically scaled by the total Mg throughput. In addition, the model uses the linearity assumption to scale equipment size as waste compositions or separation efficiencies are varied. For example, if the aluminum fraction in the waste stream decreases while the PET fraction increases, the effective size of the eddy current separator will decrease because its total throughput will decrease, while the PET optical sorter size will increase because its total throughput will increase.

The total equipment electricity use is the sum of electricity use for each individual piece of equipment. Additional electricity is consumed by office use (e.g., lighting, air conditioning, computers) and factory floor use (e.g., lighting, fans, automated doors). This additional electricity use is allocated evenly to the material fractions on a kWh per Mg basis. An explanation of equipment resource use, including office and factory floor electricity use values, is presented in Appendix B.

Some MRFs do not have automated equipment for the separation of glass by color and plastic by type on site. Rather, they ship separate mixtures of glass and plastic to regional sorting facilities. The separation process is assumed to be the same whether the sorting takes place onsite or at a centralized regional facility, thus the electrical energy consumption is assumed to be the same. The model allows the user to include the transportation of these materials to regional facilities, if needed.

\subsection{Labor Requirement Calculations}

MRFs employ people in several positions, including rolling stock drivers, laborers, and supervisors. Because the hourly wage rates of different employees may differ, labor requirements are tracked separately for each employee category. For example, the default hourly wage rate for drivers and laborers, based on discussions with MRF operators, is $\$ 10$ and $\$ 12$, respectively. Drivers are only needed to operate rolling stock. All other non-supervisory labor is performed by laborers. The number of supervisors is not an explicit model input. Instead, salary for supervisors is accounted for in the management rate, expressed as a fraction of the labor rate, and assumed to be $50 \%$ in this analysis. This management rate is combined with a fringe benefit rate and the appropriate base wage to calculate effective wages for laborers and drivers. The labor requirement (laborer hours per Mg throughput) 
1 associated with equipment operation and negative sorting is calculated based on the total number of

2 laborers required for operation, which is an input. The value for the total number of laborers per piece of

3 equipment does not have to be an integer since laborers may have duties at multiple stations throughout

4 the day. The number of laborers is divided by the equipment throughput to calculate the total number of

$5 \quad$ laborer hours required per Mg throughput, as shown in Equation 4.

$6 \quad L_{j}^{A E}=\frac{n_{j}^{\text {laborers }}}{m_{j}^{M T P} \cdot f_{j}^{M T P}}$

7

8

where:

$$
L_{j}^{A E}
$$

$n_{j}^{\text {laborers }}$

$$
m_{j}^{M T P}
$$

$f_{j}^{M T P}$ labor requirement for equipment $j$ in the set of automated separation equipment and negative-sorts (laborer hours per Mg throughput) number of laborers required to operate equipment $j$ maximum throughput (MTP) mass of equipment $j(\mathrm{Mg})$ fraction of equipment capacity utilized

When manual sorting is specified in place of automated separation, the labor requirement calculation is adjusted accordingly. The mass removed at a positive-sorting station, which is calculated in the mass balance, is divided by the mass of the material an individual picker can recover in an hour (i.e., the picking rate) to estimate the labor requirement (Equation 5). Default picking rates for all recovered materials are presented in Appendix A, Table A5.

$L_{j}^{M P S}=\frac{m_{j}^{\text {removed,total }}}{m_{j}^{T P} \cdot r_{j}^{\text {picking }}}$

where:

$$
L_{j}^{M P S}
$$

$m_{j}^{\text {removed,total }}$

total mass removed at picking station $j(\mathrm{Mg})$

$m_{j}^{T P}$ throughput mass of picking station $j(\mathrm{Mg})$ 


$$
r_{j}^{\text {picking }}
$$

picking rate associated with equipment $j$ (For example, a positive sort targeting aluminum would have an aluminum picking rate.) (Mg material per laborer hour)

The total facility laborer requirement is calculated in a similar manner to the total facility electricity use. The laborer requirement per Mg of material processed by equipment $j$ is multiplied by the throughput of equipment $j$. The equipment-specific laborer requirements are then summed over all pieces of MRF equipment. The facility driver requirement is calculated following the same procedure.

\subsection{Cost Estimation}

This model uses capital, material, and labor cost data along with the calculated mass balance, labor requirements, and resource consumption to estimate the total cost per unit input mass using Equation 6:

$C^{\text {total }}=C^{N E C}+C^{E q}+C^{L}+C^{R}$

where:

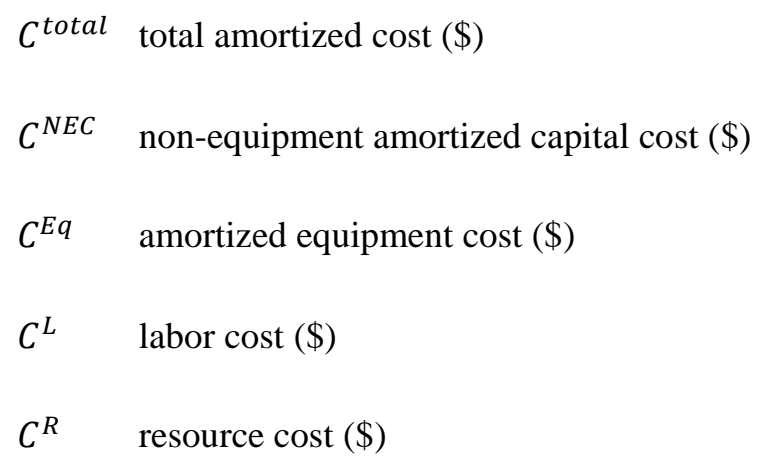

The amortized cost, in U.S. dollars (\$) per Mg summed over all waste fractions, is calculated from the capital costs for building construction and equipment purchase as well as the annual costs for personnel, diesel and electrical energy, and other operating costs (Equation 6). The capital costs associated with equipment and building acquisition are amortized, or converted from a single lump sum cost in the first year to an annual cost over the MRF lifetime, using a 5\% discount rate and an estimated equipment lifetime, shown in Table 4. The amortized building and land costs are summed to represent the nonequipment capital cost, $\mathrm{C}^{\mathrm{NEC}}$. The amortized equipment capital cost and annual equipment maintenance cost are summed to represent the total equipment cost, $\mathrm{C}^{\mathrm{Eq}}$, as shown in Appendix B, Equation B5. The 
1 labor cost, $\mathrm{C}^{\mathrm{L}}$, includes the general labor cost and driver cost, with supervision and fringe multipliers, as 2 shown in Appendix B, Equation B8. The resource cost, $C^{R}$, includes the cost of electricity and diesel used 3 within the facility and the cost of wire to bale recovered materials. Appendix B.2 presents calculations 4 for each term in Equation 6. 
Table 4 Throughput, energy requirement, cost, and labor data for each piece of automated equipment (based on Combs (2012))

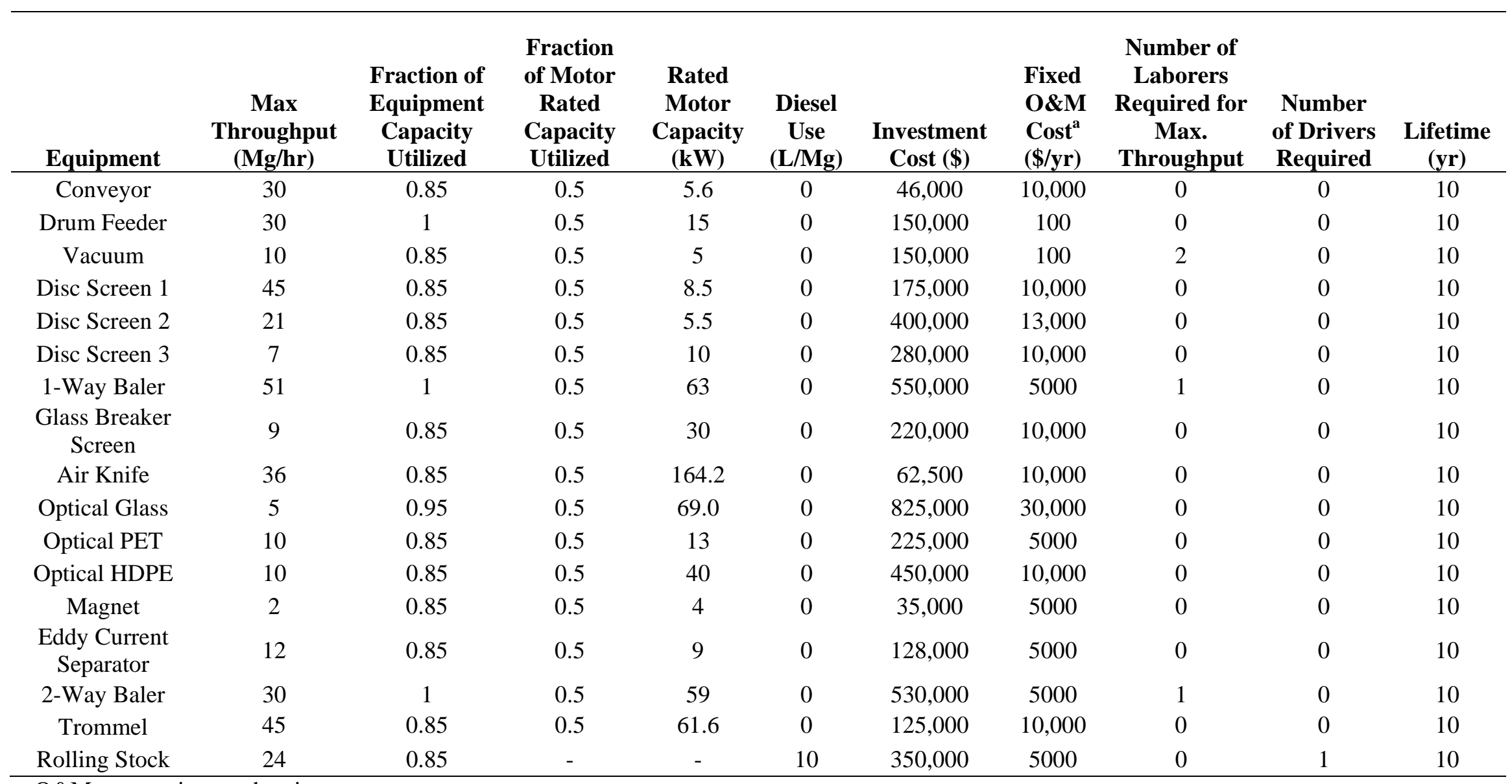

2

a. O\&M = operations and maintenance 


\subsection{Allocation}

Total costs and energy consumption are allocated to individual waste fractions so that model performance is responsive to waste composition. Furthermore, optimization of waste flows through a solid waste system, as in SWOLF, requires energy and costs to be allocated to individual waste components to determine the optimal technology choices and mass flows through an integrated solid waste system. For example, given a specific model objective (e.g., minimize GHG emissions), SWOLF calculates whether recycling paper to avoid virgin paper production is preferable to landfilling paper or combustion with energy recovery. Thus, all energy and costs must be allocated to individual waste fractions.

The allocation method is mass-based and varies based on the attributes of the equipment. For equipment that is used to remove and recover one or more waste fractions, the resource use and cost for the total throughput are allocated to only the removed materials. For example, the magnet and eddy current separator energy consumption and costs are allocated only to ferrous and aluminum, respectively, because those are the materials in the waste composition that necessitate the use of that equipment. In contrast, some equipment separates two streams that contain recoverable materials (i.e., disc screens, glass breaker screens). In this case, costs and resource use are allocated to the total throughput. For equipment that does no separation (i.e., drum feeders, balers, rolling stock), the allocation is also based on total throughput. Future analyses may require allocation of resource use and cost to streams different than those presented here (e.g., combustibles to waste-to-energy), so the model allows the user to allocate resource use and cost to the equipment's input stream, the residual output stream, or the product output streams.

\subsection{Development of Model Input Data}

Information on the cost, capacity, and energy consumption for each piece of equipment was obtained through contact with vendors and MRF operators as summarized in Combs (2012). Discussions with MRF operators and equipment vendors were required to document current state-of-the-art technology and facility configuration. A complete list of model input data is presented in Appendix C.

\section{Results and Discussion}

To examine MRF cost and performance, the model was used to calculate mass flows, energy requirements, and cost per unit mass input for each MRF type. The mass flows were used to calculate recovery rates for all recyclable materials, which are important in solid waste LCAs that consider downstream processing of sorted waste. Electricity and rolling stock fuel requirements were calculated, 
1 which can be used to estimate the associated emissions. Total facility costs were estimated for each MRF

2 type. Sensitivity analysis on equipment separation efficiencies and waste composition was performed for

3 the single-stream MRF. Though four MRF types are presented in this analysis, meaningful direct

4 comparison across MRF types is inappropriate because the mixed waste MRF has a different functional

5 unit, owing to the different waste composition it accepts relative to the others. Though not modeled in this

6 analysis, different waste collection schemes must be considered to account for differences in upstream

7 waste flow.

\subsection{Material Recovery Rates for Each MRF Type}

Using the mass balances from each MRF model and the assumed separation efficiencies, recovery rates for all recycled materials were derived and are shown in Table 5. Metal recovery rates are the highest, with recoveries ranging from $87 \%$ to $100 \%$ for aluminum and ferrous. OCC is recovered at a higher rate than non-OCC fiber in all MRF types. Mixed-waste MRFs have a lower fiber recovery rate because high contamination rates reduce separation efficiencies. HDPE and PET have similar recovery rates, ranging from $83 \%$ to $100 \%$. Glass recovery rates range from $93 \%$ to $95 \%$, except in the mixedwaste MRF, where a trommel removes some broken glass with the organic fraction, lowering the recovery rate to $69 \%$. The pre-sorted MRF removes fewer contaminants from input waste streams, which reduces the percentage of input mass that is not recovered (i.e., residual rate) below those in the dualstream and single-stream MRFs. The dual-stream recovery rates are lower than the single-stream rates because the fiber stream is assumed to contain $1 \%$ of the container stream and vice versa. This contamination also increases the dual-stream MRF's residual rate. 
Table 5 Calculated recovery and residual rates by MRF type and material (\%). Though the single-stream, dual-stream, and pre-sorted MRFs have similar recovery rates, the high contaminant rate in the mixedwaste MRF reduces recovery efficiency and increases the residual rate.

\begin{tabular}{|c|c|c|c|c|c|c|c|c|c|}
\hline MRF Type & $O_{C C}{ }^{a}$ & $\begin{array}{l}\text { Non- } \\
\text { OCC } \\
\text { Fiber }\end{array}$ & Al & $\mathbf{F e}$ & Film & HDPE & PET & Glass & $\begin{array}{c}\text { Residual } \\
\text { Rate }^{\text {b }}\end{array}$ \\
\hline Single-Stream & 100 & 99 & 97 & 98 & 90 & 98 & 98 & 95 & 10 \\
\hline Mixed-Waste & 76 & 39 & 87 & 88 & 77 & 83 & 83 & 69 & 76 \\
\hline Dual-Stream & 99 & 98 & 96 & 97 & 0 & 97 & 97 & 93 & 11 \\
\hline Pre-Sorted & 100 & 100 & 100 & 100 & 0 & 100 & 100 & 95 & 2 \\
\hline
\end{tabular}

${ }^{a}$ OCC recovery rate includes OCC removed by disc screens 2 and 3 that is baled as mixed paper.

${ }^{\mathrm{b}}$ Residual rate represents the percentage of incoming waste that is not recovered and requires additional downstream treatment.

Because the mixed-waste MRF has a different input waste composition, its recovery rates are not directly comparable to the other MRF types. Since there is no source-separation of recyclables prior to arrival at the mixed-waste MRF, 76\% of the input mass is residual. Recovery rates for all MRF types reflect the fraction of material recovered from the waste stream sent to the MRF based on the default compositions given in Table 1.

\subsection{Resource Use for Each MRF Type}

Electricity, diesel, and baling wire consumption were quantified for each MRF type. The model can accommodate LPG rolling stock, but only diesel rolling stock is included in this analysis. Though diesel use is shown in Table 6, the rolling stock diesel requirement per $\mathrm{Mg}$ is a model input, as noted in Section 2.5. The data used for each MRF type are based on single-stream MRF survey results (Combs, 2012). Wire use is inversely correlated to the residual rates. Higher residual rates cause low wire consumption per $\mathrm{Mg}$ of waste input since the residuals are not baled. Thus, the pre-sorted MRF requires more wire per $\mathrm{Mg}$, since only $2 \%$ of the each input $\mathrm{Mg}$ is residual. Note that if waste composition changes such that the fraction of lighter recyclable materials (i.e., plastics) increases, wire requirements per Mg would likely increase because the wire requirement per mass of baled material is relatively high for plastics given their lower density. 
Table 6 Resource use for each MRF type. More automation in the mixed-waste MRF causes higher electricity consumption. The low residual and limited automation of the pre-sorted MRF result in larger wire consumption and lower electricity consumption.

\begin{tabular}{lccc}
\hline MRF Type & $\begin{array}{c}\text { Electricity } \\
\left(\mathbf{k W h} / \mathbf{M g}_{\text {input }}\right)\end{array}$ & $\begin{array}{c}\text { Diesel } \\
\left(\mathbf{L} / \mathbf{M g}_{\text {input }}\right)\end{array}$ & $\begin{array}{c}\text { Wire Mass } \\
\left(\mathbf{k g} / \mathbf{M g}_{\text {input }}\right)\end{array}$ \\
\hline Single-Stream & 6.2 & 0.7 & 0.6 \\
Mixed-Waste & 7.8 & 0.7 & 0.3 \\
Dual-Stream & 6.0 & 0.7 & 0.6 \\
Pre-Sorted & 4.7 & 0.7 & 0.7 \\
\hline
\end{tabular}

Electricity use is highest in the mixed-waste MRF because a larger mass of contaminants is carried through the system, requiring larger equipment capacities to process the extra material. Since the fiber separation equipment does not have to accommodate the container stream in the dual-stream MRF, it uses less electricity than in the single-stream MRF. The pre-sorted MRF electricity use is much less than the other MRFs due to the limited amount of separation equipment. However, the input streams to the pre-sorted MRF are likely a result of curbside sorting, which consumes more fuel than other collection schemes. Thus, integrated analyses of SWM systems are required to quantify relative environmental performance of alternatives for recyclable recovery.

Examination of electricity consumption allocated to each recovered material reveals large variations in resource consumption by material. However, electricity use is a result of both separation technology and the fraction of the material in the final residual stream. Table 7 shows that per material electricity consumption generally follows total MRF electricity consumption, with the highest values for a mixed-waste MRF. HDPE recovery uses more electricity than all other materials, due to the high energy use per Mg of the HDPE optical sorter, in all MRFs except the pre-sorted MRF, which does not include an HDPE optical sorter. Ferrous recovery requires more electricity than aluminum recovery, except in the pre-sorted MRF where consumption is equal, due to separation using identical conveyors, manual sorts, and balers, that employs neither a magnet nor an eddy current separator. Because OCC, non-OCC fiber, and film are removed early in the process via equipment with relatively low electricity consumption, they use less electricity than other materials. Note all values in Table 7 have been normalized to the mass of material input. These values must be combined with a waste composition to calculate MRF resource use values. 
1 Table 7 Electricity consumption (kWh per Mg material) by recovered material in each MRF type.

2 Materials (i.e., glass, HDPE, PET) removed via equipment with high electricity demands (i.e., optical

3 sorters) have higher electricity consumption, as do materials that travel farther through the process (i.e., 4 aluminum and ferrous).

\begin{tabular}{lcccc}
\hline $\begin{array}{l}\text { Recovered } \\
\text { Material }\end{array}$ & $\begin{array}{c}\text { Single- } \\
\text { Stream }\end{array}$ & $\begin{array}{c}\text { Mixed- } \\
\text { Waste }\end{array}$ & $\begin{array}{c}\text { Dual- } \\
\text { Stream }\end{array}$ & $\begin{array}{c}\text { Pre- } \\
\text { Sorted }\end{array}$ \\
\hline OCC & 2.6 & 4.7 & 3.4 & 2.7 \\
Non-OCC Fiber & 3.0 & 5.4 & 3.8 & 2.7 \\
Aluminum & 9.7 & 28.1 & 6.1 & 3.1 \\
Ferrous & 11.7 & 52.0 & 7.8 & 3.1 \\
Film & 3.0 & 4.7 & 2.1 & 3.1 \\
HDPE & 32.7 & 116.1 & 22.0 & 3.1 \\
PET & 9.9 & 36.9 & 6.9 & 3.1 \\
Glass & 16.8 & 36.4 & 14.8 & 14.0 \\
\hline
\end{tabular}

Equipment electricity consumption varies based on throughput and motor size. The glass optical sorter and air knife, which are required for glass separation, consume $28 \%$ of the total single-stream MRF electricity for the default composition, as shown in Figure 2. Disc screens, which separate fiber, consume less than $10 \%$ of MRF electricity, as do the plastic optical sorters. The magnet and eddy current separator are responsible for only 3\% of MRF electricity consumption. Thus, a decrease in the glass fraction will result in greater reductions to total single-stream MRF electricity consumption than comparable decreases in other waste fractions. Electricity consumption by equipment for all MRFs is in Appendix A Table A6. 


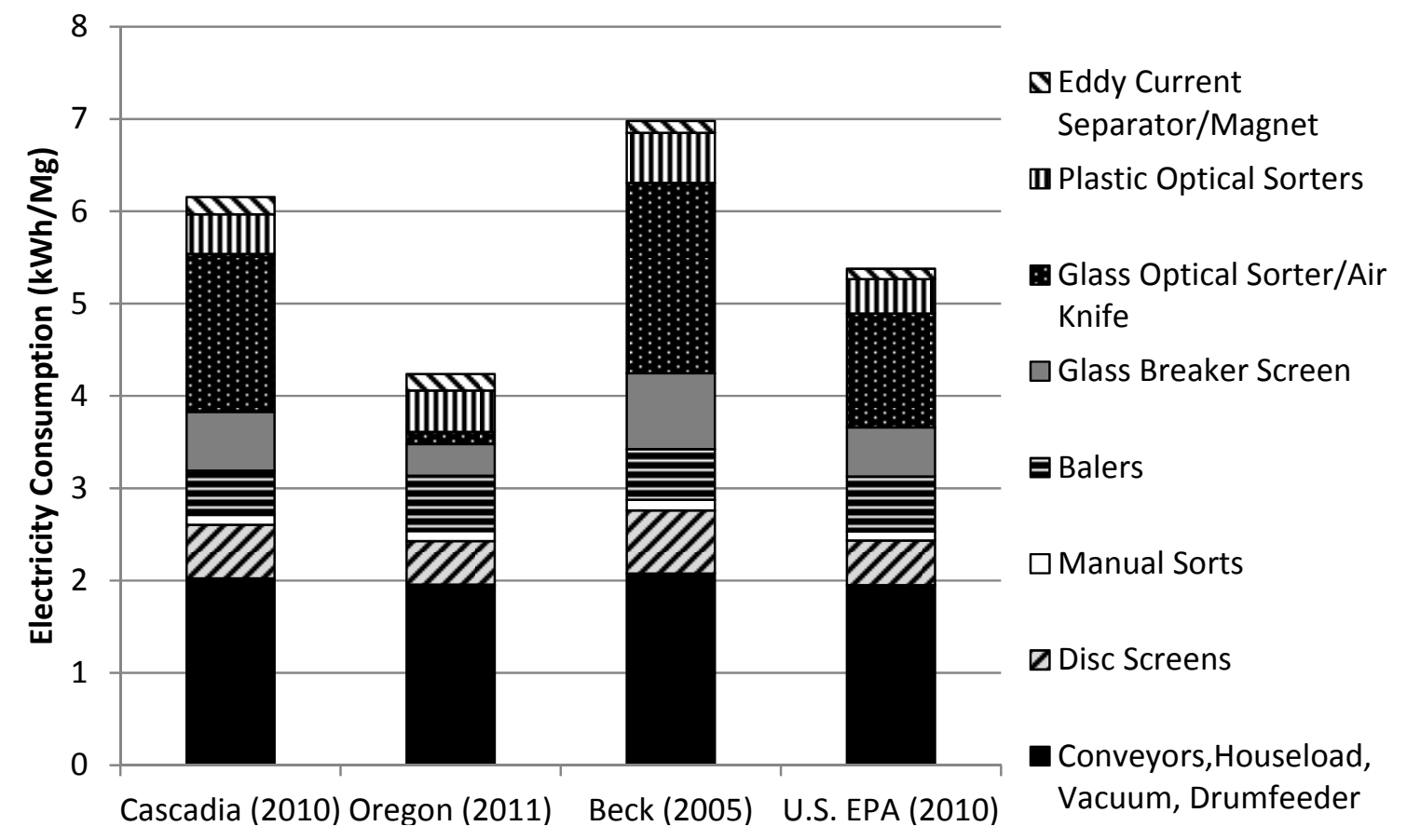

2 Figure 2 Sensitivity of single-stream MRF electricity use to waste composition

Several previous studies have reported MRF resource consumption and cost. Fitzgerald et al. (2012) found 0.8 and $0.7 \mathrm{~L}$ per Mg of diesel consumption in dual-stream and single-stream MRFs, respectively, which are comparable to the consumption values used in this analysis (Table 6). Fitzgerald et al. (2012) also reported electricity consumption of 11.5 and $13.8 \mathrm{kWh}$ per $\mathrm{Mg}$ for the dual-stream and single-stream MRFs, respectively, which are approximately double the values calculated in this analysis. The discrepancy in electricity consumption may be the result of increasing economies of scale, since most of the MRFs surveyed for this study were larger than those in the Fitzgerald study. Furthermore, the level of automation and type of lighting used in the Fitzgerald study is unknown. Chester (2008) presents electricity consumption values comparable to the results of this study, but the Chester MRFs have less automation. However, Chester's MRFs have less than 25\% of the mass throughput of the MRFs surveyed in Combs (2012), which were adapted for this analysis. The lighting estimate used for the operating floor in this analysis represents energy efficient $\mathrm{T} 5$ fluorescent bulbs, which consume $7 \%$ of total single-stream MRF electricity.

\subsection{Costs for Each MRF Type}

The cost per Mg input for each MRF type includes costs for the purchase and maintenance of equipment, labor, wire, fuel, electricity, and the capital costs associated with land procurement and building construction. The largest fraction of the total cost is the capital cost of land procurement and 
building construction, which ranges from $49 \%$ to $62 \%$ of the total cost. Of course, both of these factors will vary with location. Land procurement and building construction are the same between MRF types because the same land and construction data were used. The equipment costs range from $17 \%$, for the pre-sorted MRF with less separation equipment, to $32 \%$ of total cost, for the mixed-waste MRF that must have larger equipment to handle the large residual fraction throughout. The labor costs for single-stream and dual-stream MRFs, shown in Table 8, are much larger than the \$1.7 and \$1.5 per Mg for mixed-waste and pre-sorted MRFs respectively. The mixed-waste MRF labor cost per unit mass is much lower because labor costs are distributed over a larger quantity of waste. The labor costs are smaller in a presorted MRF because less separation is required relative to the other MRF types. The wire costs in Table 8 are directly proportional to wire consumption presented in Table 6 and have been included here because they contribute up to $8 \%$ of the total cost.

Table 8 Cost summary by MRF type. The single-stream MRF has the highest total cost because of its relatively high equipment and labor costs, while the low equipment and labor costs in a pre-sorted MRF contribute to its low total cost.

\begin{tabular}{|c|c|c|c|c|c|c|}
\hline MRF Type & $\begin{array}{c}\text { Total } \\
\text { Equipment } \\
\text { Cost (\$/Mg } \\
\text { input) }\end{array}$ & $\begin{array}{l}\text { Labor } \\
\text { (\$/Mg } \\
\text { input) }\end{array}$ & $\begin{array}{c}\text { Wire Cost } \\
\text { (\$/Mg } \\
\text { input) }\end{array}$ & $\begin{array}{c}\text { Fuel and } \\
\text { Electricity } \\
\text { Cost (\$/Mg } \\
\text { input) }\end{array}$ & $\begin{array}{c}\text { Building } \\
\text { and Land } \\
\text { Capital } \\
\text { Costs }(\$ / M g \\
\text { input per } \\
\text { year) }\end{array}$ & $\begin{array}{c}\text { Total Costs } \\
\text { (\$/Mg } \\
\text { input) }\end{array}$ \\
\hline $\begin{array}{l}\text { Single- } \\
\text { Stream }\end{array}$ & 5.8 & 4.3 & 1.3 & 1.3 & 12.3 & 24.9 \\
\hline $\begin{array}{l}\text { Mixed- } \\
\text { Waste }\end{array}$ & 7.7 & 1.7 & 0.5 & 1.5 & 12.3 & 23.6 \\
\hline $\begin{array}{c}\text { Dual- } \\
\text { Stream }\end{array}$ & 5.3 & 3.3 & 1.2 & 1.3 & 12.3 & 23.4 \\
\hline Pre-Sorted & 3.3 & 1.5 & 1.5 & 1.2 & 12.3 & 19.8 \\
\hline
\end{tabular}

${ }^{\mathrm{a}}$ Individual values may differ slightly from the total due to rounding.

The single-stream MRF has the highest total cost of \$24.9 per Mg input. The dual-stream MRF is less expensive to operate, in part, because processing two streams allows the fiber separation equipment that is placed early in the single-stream process to be smaller in a dual-stream MRF. Though the mixedwaste MRF has much larger equipment costs, the smaller labor and wire costs result in a total unit cost that is less than the single-stream MRF. Of course, the total throughput and mass of residuals are considerably higher for a mixed waste MRF. The pre-sorted MRF is less complex, resulting in the lowest equipment, labor, fuel, and electricity costs. 
MRF costs have been previously explored, but they focus on small MRFs with little automation and high labor requirements. Thus, many of these costs are higher than the costs presented in this analysis. Chester et al. (2008) reported capital and maintenance costs ranging from 10 to $30 \%$ greater than this analysis but comparable electricity values. Franchetti (2009) has total dual-stream MRF costs $90 \%$ greater than the costs presented here, largely due to the representation of a more labor intensive process.

\subsection{Parametric Analysis of Waste Composition and Equipment Separation Efficiencies in a Single-}

\section{Stream MRF}

To explore model response to different waste compositions, the single-stream model was run with the default and three additional waste compositions as given in Appendix A, Table A1. The default waste composition, from Cascadia (2011), quantifies the composition of the household-separated recyclable stream in Seattle, Washington. Contaminants make up 5.9\% of the incoming waste. Beck (2005) reported the statewide commingled recycling stream composition for Pennsylvania. No contaminants were included in the composition. ODEQ (2011) reported residential commingled recyclable composition, which is influenced by the fact that container glass as well as plastic and aluminum containers have deposits and are partially recovered outside of the residential recyclable stream. This explains the relatively low (1.4\%) glass content in the ODEQ recyclables stream. Because the purpose of this sensitivity analysis is to explore model response to waste composition variation, the model recovered glass and film for all waste compositions, though glass and film would probably not be recovered for compositions like ODEQ (2011). Other contaminants in the ODEQ (2011) composition made up 5.7\% of the incoming mass, which is the sum of the non-recyclable paper, non-recyclable plastic, and miscellaneous inorganics in Appendix A, Table A1. U.S. EPA (2010) was used to estimate a commingled recyclables composition, by combining masses of recovered materials. This composition does not isolate the residential stream, so $40 \%$ of the mass is OCC. Like Beck (2005), no contaminants are included in this waste composition, so the resulting residual rate is much lower than residuals for the ODEQ (2011) and Cascadia (2011) streams. Electricity consumption under all four waste compositions is provided in Figure 2.

The effect of waste composition on electricity consumption and cost is presented in Table 9 and Figure 2. The changes in cost are a result of changes to equipment as well as changes to electricity and wire consumption. The costs for the different waste compositions are within $7 \%$ of the average, which is likely well within the model uncertainty. Though the ODEQ (2011) composition has a large residual rate, its electricity consumption and total cost are less than the other waste compositions. Much of the 
1 comparative savings can be attributed to decreased size and electricity consumption of the glass breaker

2 screen and glass optical sorter, as shown in Figure 2. Beck (2005) has the highest electricity consumption

3 due in part to its high glass content (21\%), which increases the electricity consumption by the glass

4 breaker screen and glass optical sorter. Baler electricity use per Mg is smaller because the Beck

5 composition includes contaminants as well as glass, which results in more unbaled material than the other

$6 \quad$ MRF types.

7 Table 9 Model response to variations in waste composition in a single-stream MRF

\begin{tabular}{lcccc}
\hline Result & Cascadia (2011) & ODEQ (2011) & Beck (2005) & U.S. EPA (2010) \\
\hline Residual Rate (\%) & 10 & 9 & 2 & 2 \\
Electricity Consumed & 6.2 & 4.2 & 7.0 & 5.4 \\
$(\mathrm{kWh} / \mathrm{Mg})$ & 24.9 & 23.9 & 26.6 & 24.3 \\
Total Cost $(\$ / \mathrm{Mg})$ & & & & \\
\hline
\end{tabular}

8

To explore the effects of separation efficiencies on electricity consumption within a single-stream MRF, the separation efficiencies for sorting equipment were altered one piece of equipment at a time, by subtracting 25\% from all non-zero separation efficiencies, as presented in Appendix A Table A7. The percent change in electricity compared to the default electricity consumption was used as a metric to examine the relative impact of each piece of equipment's separation efficiency values (Figure 3).

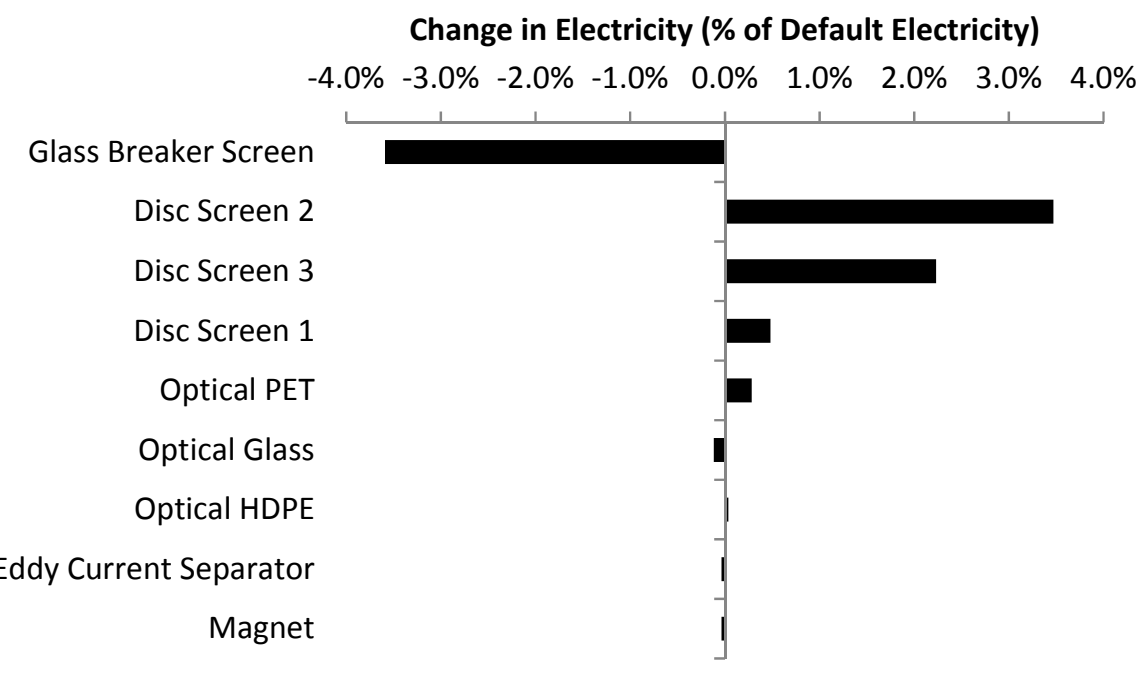

14
Figure 3 Parametric sensitivity analysis for a 25\% decrease in separation efficiencies for selected equipment within a single-stream MRF. MRF equipment is ordered from top (largest effect) to bottom (smallest effect). 
When the separation efficiency of the glass breaker screen is reduced, more glass contaminates the containers stream, which necessitates increasing the size of equipment meant to separate containers. However, this increase in equipment size is offset by the reduction in downstream equipment size and thus electricity demand due to the decreased throughput of the air knife and glass optical sorter. Reducing the separation efficiencies of a glass breaker screen by $25 \%$ results in a $3.6 \%$ decrease in single-stream MRF electricity consumption. As the separation efficiency of a disc screen decreases, additional paper goes to downstream equipment, and the increased electricity demand of downstream equipment exceeds the savings at the disc screen. Disc screen 2 produces the largest change among the disc screens because it is the first screen to process the non-OCC fiber stream, and it processes the $30 \%$ of OCC not removed by disc screen 1 . Reducing the PET optical sorter separation efficiencies slightly increases the electricity demand because of increased downstream equipment size. The effect of changing any other equipment's separation efficiencies results in a change to total electricity consumption less than $0.1 \%$, which is less than the precision of the model. While changes in separation efficiency do not have a significant effect on MRF performance, they may have a large impact on the performance of downstream processes, which are not accounted for in this analysis. For example, higher levels of contaminants in the paper stream can affect the paper recycling process by limiting the type and quality of recycled paper that can be produced from it (Miranda et al., 2013).

\subsection{Comparison with operating MRF}

To evaluate the MRF model described here, electricity consumption from an operating MRF was compared with estimates from the single-stream MRF model. Model inputs were adjusted to match the equipment layout and facility size of the actual MRF described in Combs (2012) as closely as possible. Additionally, the lighting electricity use from Combs (2012) was used because the model defaults are for energy efficient fluorescent lighting, which was not installed at the surveyed MRF. Input waste composition data was not available for the operating MRF, so the default composition from Table 1 was used. The model estimates electricity consumption to be $24.3 \mathrm{kWh}$ per Mg, while the actual MRF consumption was $23.8 \mathrm{kWh}$ per Mg. Thus, the model overestimated the MRF's electricity consumption by only $2 \%$.

As shown in Table 9, when the model is used with default values, MRF electricity consumption is estimated to be $6.2 \mathrm{kWh}$ per $\mathrm{Mg}$, which is nearly a factor of 4 lower than the estimate for the actual MRF discussed above. The default values assume modern lighting and small office space, which each contribute $8 \%$ of total MRF electricity use, but the surveyed MRF was modeled with large office space and older lighting, which contributed $17 \%$ and $69 \%$ of the total MRF electricity use, respectively. These 
results serve to emphasize the importance of a MRF process model that is responsive to waste composition, process flow, and facility design (e.g., lighting technology).

\subsection{Conclusions}

The model presented here quantifies MRF cost and energy consumption over a broad set of conditions. The MRF model represents a significant improvement over fixed estimates of MRF electricity consumption, since MRF performance can vary significantly depending on facility design and incoming waste composition. The model can also allocate electricity use to each waste fraction, enhancing the capability of SWM LCA models such as SWOLF. The model described here is the first to both represent a modern automated MRF and respond to changes in MRF facility design.

The results show that resource demands and costs associated with MRF operation vary by both MRF type and input waste composition. The electricity use associated with glass separation equipment is greater than all other types of separation equipment. Thus, energy efficiency gains associated with the glass separation technology will result in larger reductions in facility electricity consumption than any other equipment. The floor area per $\mathrm{Mg}$ of facility throughput and the installed lighting technology in the separation area have the potential to impact total facility electricity consumption. Because of the small contribution of resource use to total cost, increased electrical and fuel efficiency will not significantly affect MRF costs. Due to high capital costs, varying waste composition resulted in small changes to total costs in the single-stream MRFs. However, the range in electricity consumption in response to variations in waste composition was more than $40 \%$ of the baseline electricity consumption. Though there is uncertainty in separation efficiencies, sensitivity analysis revealed large reductions to individual equipment separation efficiencies resulted in only small changes in total electricity consumption within the MRF, though potential downstream effects were not quantified.

Narrow system boundaries were purposely established in this analysis to isolate MRF cost and performance. This model and associated results can be integrated into LCAs with broader system boundaries to evaluate waste management from curbside collection through final disposal. Though presorted MRFs ostensibly appear to be cheaper, less energy-intensive, and less GHG intensive than other MRF types, MRF performance must be considered in the context of the larger solid waste management system. For example, pre-sorted MRFs typically receive the separated streams from systems with curbside separation, which results in higher collection fuel consumption and cost compared to singlestream collection. Consideration of waste collection options associated with each MRF type, disposal options for residual waste, and avoided emissions associated with the recovered materials are important considerations in any integrated systems analysis of solid waste management. 


\section{Acknowledgements}

2 This research was supported by theNational Science Foundation and the Environmental Research and 3 Educational Foundation 


\section{References}

(R.W.) Beck, 2005. Pennsylvania Recovered Material Composition Study.

(State of) California, 2012. California’s new goal: 75\% recycling. CalRecycle. http://www.calrecycle.ca.gov/75percent/Plan.pdf

Cascadia (Consulting Group), 2011. Residential Recycling Stream Composition Study Final Report.

Chester, M., Martin, E., Sathaye, N., 2008. Energy, Greenhouse Gas, and Cost Reductions for Municipal Recycling Systems. Environ. Sci. Technol. 42, 2142-2149.

Combs, A.R., 2012. Life-Cycle Analysis of Recycling Facilities in a Carbon Constrained World. North Carolina State University, Raleigh, North Carolina, United States. http://repository.lib.ncsu.edu/ir/bitstream/1840.16/7808/1/etd.pdf

Ecoinvent Data V2.2, 2010. Swiss Centre for Life-cycle Inventories.

EU (European Union), 2008. Directive 2008/98/EC of the European Parliament and of the Council of 19 November 2008 on waste and repealing certain Directives Text with EEA relevance. Official Journal 312 , 0003 - 0030

FDEP(Florida Department of Environmental Protection), 2010. 75\% Recycling goal report to legislature. http://www.dep.state.fl.us/waste/quick_topics/publications/shw/recycling/ 75percent/75_recycling_report.pdf.

Fitzgerald, G.C., Krones, J.S., Themelis, N.J., 2012. Greenhouse gas impact of dual stream and single stream collection and separation of recyclables. Resources, Conservation and Recycling 69, 50-56.

Franchetti, M.J., 2009. Case study: Determination of the economic and operational feasibility of a material recovery facility for municipal recycling in Lucas County, Ohio, USA. Resources, Conservation and Recycling 53, 535-543.

Laurent, A., Clavreul, J., Bernstad, A., Bakas, I., Niero, M., Gentil, E., Christensen, T.H., Hauschild, M.Z., 2014. Review of LCA studies of solid waste management systems--part II: methodological guidance for a better practice. Waste Manag. 34, 589-606.

Levis, J. W.; Barlaz, M. A., DeCarolis, J. F., Ranjithan, S. R., 2013. A generalized multistage optimization modeling framework for life-cycle assessment-based integrated solid waste management. Environ. Modell. Softw., 50, 51-65 
Merrild, H., Larsen, A.W., Christensen, T.H., 2012. Assessing recycling versus incineration of key materials in municipal waste: The importance of efficient energy recovery and transport distances. Waste Management 32, 1009-1018.

Miranda, R., Monte, M.C., Blanco, A., 2013. Analysis of the quality of the recovered paper from commingled collection systems. Resources, Conservation and Recycling 72, 60-66.

Nishtala, S.R., 1995. Design and analysis of material recovery facilities in an integrated solid waste management system. North Carolina State University, Raleigh, North Carolina, United States.

(City of) Oakland, 2013. OaklandRecycles Website. http://www2.oaklandnet.com/Government/o/PWA/o/FE/s/GAR/OAK024364.

ODEQ (Oregon Department of Environmental Quality), S.W.P. and P.D.S.L.Q.D., 2011. Composition of Commingled Recyclables Before and After Processing.

San Francisco Environment, 2013. Zero Waste Website. http://www.sfenvironment.org/zero-waste.

(City of) Seattle, 2013. Zero Waste Strategy Website.

http://www.seattle.gov/council/issues/zerowaste.htm.

Rotter, V.S., Kost, T., Winkler, J., Bilitewski, B., 2004. Material flow analysis of RDF-production processes. Waste Management 24, 1005-1021. doi:10.1016/j.wasman.2004.07.015

Themelis, N.J., Todd, C.E., 2004. Recycling in a Megacity. Journal of the Air \& Waste Management Association 54, 389-395.

U.S. EPA (United States Environmental Protection Agency), 2012. Municipal Solid Waste Generation, Recycling, and Disposal in the United States: Facts and Figures for 2011.

U.S. EPA (United States Environmental Protection Agency), 2010. Municipal Solid Waste Generation, Recycling, and Disposal in the United States: Facts and Figures for 2009.

Velis, C.A., Longhurst, P.J., Drew, G.H., Smith, R., Pollard, S.J.T., 2010. Production and Quality Assurance of Solid Recovered Fuels Using Mechanical—Biological Treatment (MBT) of Waste: A Comprehensive Assessment. Critical Reviews in Environmental Science and Technology 40, 9791105. doi:10.1080/10643380802586980 
1 Velis, C.A., Wagland, S., Longhurst, P., Robson, B., Sinfield, K., Wise, S., Pollard, S., 2013. Solid 2 Recovered Fuel: Materials Flow Analysis and Fuel Property Development during the Mechanical

3 Processing of Biodried Waste. Environ. Sci. Technol. 47, 2957-2965. doi:10.1021/es3021815

4 